\title{
Shadow of doubts: Melencolia von Albrecht Dürer
}

Enrico Danieli

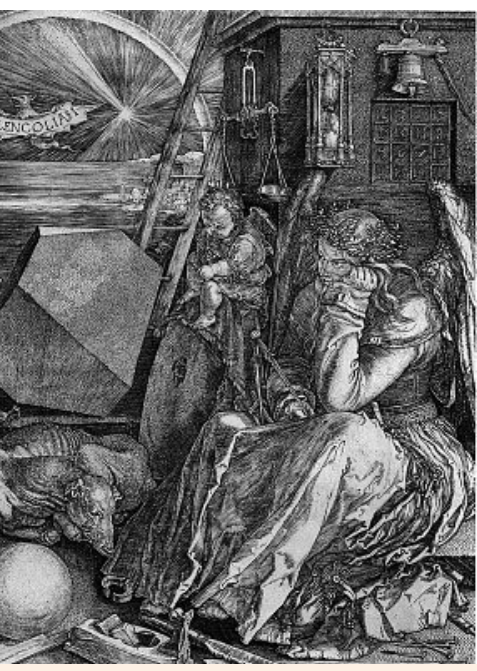

«Melencolia» - Kupferstich von Albrecht Dürer aus dem Jahr 1514.
1 Klibansky R, Panofsky E, Saxl F. Saturn und Melancholie. Frankfurt a. M.: Suhrkamp Taschenbücher Wissenschaft; 1992.

Korrespondenz: Dr. med. Enrico Danieli Via ai Colli 22 CH-6648 Minusio

e.b.danieli@bluewin.ch
Es gibt Bilder, die, einmal gesehen, einen nicht mehr loslassen, mehr noch: nicht nur, dass sie selbst in den Träumen auferstehen, sondern auch, dass diese Erinnerung an sie oftmals an die Umstände (den Ort, die Zeit) unserer ersten Bekanntschaft gekoppelt bleibt. Dürers Kupferstich Melencolia gehört zu dieser seltenen Form von Bild. Und dass dann ein gewaltiges Buch [1] zu diesem Thema uns beinahe erschlägt, zu genauem Hinschauen zwingt, werden alle diejenigen verstehen, denen es mit diesem Bild ähnlich ergeht.

Was lässt sich aus einem Buch von über 700 Seiten an Wichtigem zusammenfassen? Lesen, sehen und verstehen lernen! Ohne auf Details einzugehen zum Thema Saturn und Melancholie, zur Studie der Geschichte der Melancholie, zur Naturphilosophie der Melancholie, zur Medizin und zur Religion kann beruhigenderweise festgestellt werden, dass das uns zur Zeit zum Thema Melancholie Denkbare umfassend zur Verfügung steht.

Dass alles seinen Anfang nimmt mit den Menschen, und wie deren Ursprung auch schon die Melancholie gleichsam als Geschwister dem Menschen zur Seite stellt, erfahren wir aus frühesten und früheren Zeiten. Antike; Problem XXX1; die Melancholie im System der Vier Temperamente; Mittelalter: Melancholie als Krankheit; früharabische Medizin; humorale Charakterlehre; Saturn: der Stern der Melancholie; Saturn in der Literatur der Antike und des Mittelalters; Saturn in der Bibelüberlieferung und in der mythographischen Illustration; die Poetische Melancholie im Spätmittelalter; die Melencholia Generosa: Melancholie als gesteigerte Selbsterfahrung im Nachmittelalter; und schliesslich die Glorifizierung der Melancholie und des Saturn im Florentiner Neuplatonismus als Beginn zur Moderne.

Erst danach, wir sind mit den Grundbegriffen zur Melencholia nun vertraut, folgen Dürers Holzschnitte und schliesslich der berühmteste Kupferstich des Abendlandes: Saturn, der Gott der Melancholiker, ist Sinnbild der Schwermut in der Todesruhe. Er ist zum Unglücksplaneten geworden, und der homo saturnus ist der schlimmste von allen Menschen (in der mittelalterlichen Überlieferung): Seine Haut ist dunkel, seine Augen sind klein, hohl, aber scharfsichtig, seine Stimme ist schwach, seine Haltung starr, sein Blick zur Erde gesenkt, er ist furchtsam, müde, traurig, einsam, trübsinnig, nachdenklich, ein scharfer Denker, und da sein Leben sich in jedem Augenblick dem Ende zuneigt, liebt er, zurückgezogen am Feuer zu sit- zen, sich zu wärmen, denn Lebenswärme schwindet ihm, und nichts anderes denkt es in ihm als vom Himmelssturz, von Unendlichkeitssehnsucht, vom Weltschmerz, von Seelenpein und von Verhemmung.

So ist es schliesslich die seit vielen Jahren sehr in Mode gekommene tiefsinnige Kontemplation - Maske oder Krankheit? -, die uns beschäftigt. Und die Trägheit (acedia), früher ein Laster, heute als ein wesentliches Krankheitsteil erkannt, bildet den Boden für die Entstehung einer Melancholie, von Musse kann also keine Rede sein. Doch ob es auch noch heute die Nobilitierung der Melancholie schafft, diese mit Genie - natürlich rein bildungsmässig - zu assoziieren? Es bleibt mit Sicherheit bestehen, dass Saturn, der Planet der Melancholie, ein Unglücksplanet ist, und dass die Melancholie ein schweres Verhängnis darstellt. Am Rande sei erwähnt, dass die Melencholia, wie die Symptomatologie eine Trias - gestört sind imaginatio (Einbildungskraft), ratio (Verstand) und intuitio (Vernunft) -, behandelt wird mit einer Diätetik (Vermeiden von jeglicher Art von Unregelmässigkeit), mit Medikamenten sowie iatromathematisch (Talismane, Amulette, später Chirurgie ...).

Endlich, nach 400 Seiten, nähern wir uns dem Bild Dürers und erfahren nun alles, was wir schon lange wissen wollten: Das Motiv des aufgestützten Kopfes ist eine uralte Ausdrucksgeste, die Trauer, Nachdenken und Müdigkeit bedeutet. Die geschlossene Faust ist Zeichen melancholischer Wahnideen; der Blick schweift in eine gegenstandslose Ferne - der unheimliche Blick entsteht aus den nach oben gerichteten Augen und aus der Divergenz der Sehachsen -; das dunkle Antlitz ist ein beschattetes, verdüstertes Gesicht; das aufgelöste Haar ist Zeichen der Seelenwirrnis; die die Geometrie symbolisierenden Werkzeuge liegen herum, nichts kann mit diesen angefangen werden: das Nichts-Tun mit leblosen Dingen als Zentrum der Beschäftigung (im müssigen Trübsinn); über die vielen weiteren zum Teil noch unausgedeuteten Details (schlafender Hund, magisches Quadrat, Geometriesymbolik in Beziehung zur schwarzen Magie, Glocke), auch über die Dreiheit von Saturn, Melancholie und Geometrie berichtet das Buch umfassend. Und ab Seite 448 wird über den neuen Sinn von Dürers Melancholie in derart erregender Weise nachgedacht, dass man das epocheübergreifende Buch nicht (nie) mehr aus der Hand legen möchte/ wird. 